\title{
Arterial stiffness, hypertension, and rational use of nebivolol
}

\author{
This article was published in the following Dove Press journal: \\ Vascular Health and Risk Management \\ 19 May 2009 \\ Number of times this article has been viewed
}

\section{Enrico Agabiti-Rosei \\ Enzo Porteri \\ Damiano Rizzoni \\ Clinica Medica, Department of Medical and Surgical Sciences, University of Brescia, Italy}

Correspondence: Prof. Enrico Agabiti-Rosei Clinica Medica, Department of Medical and Surgical Sciences, University of Brescia, Italy c/o $2^{\text {a }}$ Medicina Spedali Civili, Piazza Spedali Civili 25100 Brescia, Italy

$\mathrm{Tel}+390303995815$

$\mathrm{Fax}+300303384348$

Email agabiti@med.unibs.it
Abstract: Arterial stiffness plays a key role in the pathophysiology of the cardiovascular system. Some indices of arterial stiffness (pulse wave velocity, augmentation index, characteristics of central blood pressure waveform) may be presently calculated and evaluated in the clinical setting. Age and blood pressure are the two major clinical determinants of increased arterial stiffness, while molecular determinants of arterial stiffness are related to fibrotic components of the extracellular matrix, mainly elastin, collagen and fibronectin. Increased arterial stiffness has been consistently observed in conditions such as hypertension, dyslipidemia and diabetes. Arterial stiffness evaluated by means of carotid-femoral pulse wave velocity yielded prognostic significance beyond and above traditional risk factors. A more favorable effect of calcium channel blockers, diuretics and ACE inhibitors compared with $\beta$-blockers on indices of arterial stiffness was observed in several studies. It is conceivable that newer $\beta$-blockers with additional vasodilating properties, such as nebivolol, which has favorable effects on carbohydrate and lipid metabolism, as well as on endothelial function and on oxidative stress, may have favorable effects on arterial stiffness, compared with atenolol. In fact, in recent studies, nebivolol was demonstrated to improve artery stiffness to a greater extent than older $\beta$-blockers. Because endothelial dysfunction and increased arterial stiffness play an important role in the early atherosclerotic processes and are associated with poor outcomes and increased mortality, independently of blood pressure, the ability of nebivolol to enhance release of endotheliumderived nitric oxide, and consequently improve endothelial function and arterial stiffness, may have significant clinical implications for the use of this agent in the treatment of hypertension and cardiovascular diseases.

Keywords: arterial stiffness, hypertension, nebivolol

\section{Introduction}

Arterial stiffness plays a key role in the pathophysiology of the cardiovascular system. During systole, the left ventricle increases the pressure in large vessels, which, owing to their elastic properties, may store a significant part of the left ventricle ejection volume. ${ }^{1}$ After the closure of the aortic valve, the recoil of the large vessels to their diastolic dimensions pushes the blood towards the periphery. This mechanism allows to reconcile the intermittent contraction of the left ventricle with the permanent need of tissues for oxygen and nutriments. ${ }^{1}$ This phenomenon is quantitatively larger in healthy and younger subjects. ${ }^{2}$ Arterial compliance favors left ventricular function as it reduces left ventricular workload, and enhances diastolic perfusion, crucial to the delivery of blood to the myocardium through the coronary vessels. As the propagation of the pressure wave in elastic tubes occurs at a definite velocity, it 
is possible to measure arterial stiffness through the pulse wave velocity (PWV). Aortic stiffness is approximated by the carotid to femoral pulse wave velocity (typical value: $8 \mathrm{~m} / \mathrm{s}){ }^{1,3}$ In addition, the pressure wave can reflect from the peripheral vasculature (branching, resistance, stenosis), and return towards the heart. ${ }^{1}$ When stiffness is high, the returned wave may add to the ejection pressure. In physiological conditions, the reflected pressure wave returns in diastole, explaining why the systolic and pulse pressures measured close to the heart (central blood pressure) are lower than at the periphery (Figure 1). ${ }^{4}$

Age and blood pressure are the two major determinants of increased arterial stiffness. ${ }^{1,5}$ Molecular determinants of arterial stiffness are related to the fibrotic components of the extracellular matrix (ECM), mainly elastin, collagen and fibronectin. Increased arterial stiffness was consistently observed in conditions such as hypertension, dyslipidemia and diabetes. ${ }^{1}$ As blood vessels become stiffer because of agerelated processes, the pulse wave is transmitted more rapidly and returns to the heart during left ventricular contraction, resulting in a greater augmentation of the central aortic systolic pressure. It is therefore possible to quantify this effect through the calculation of the augmentation index (Figure 2).

Several studies have underlined the role of inflammation in the stiffening of large arteries. Various mechanisms may be involved, including endothelial dysfunction, release of inducible matrix metalloproteinases, medial calcifications, changes in proteoglycan composition and state of hydration, as well as cellular infiltration around the vasa vasorum leading to vessels ischemia. ${ }^{1}$ The association between arterial stiffening and inflammation in essential hypertension has been demonstrated through the relationships between arterial stiffness and either tumor necrosis factor-alpha (TNF- $\alpha$ ), interleukin-6 (IL-6), or high sensitive C-reactive protein (hs-CRP). ${ }^{6,7}$ Baseline hs-CRP was not only an independent predictor of carotid-femoral pulse wave velocity and central augmentation index, ${ }^{6}$ but also of the reduction in peripheral pulse pressure after antihypertensive treatment during the REASON study. ${ }^{7}$

\section{Arterial stiffness}

\section{as a cardiovascular risk factor}

Alterations in the mechanical properties of large arteries have a clear pathophysiological link with clinical outcome. In addition to being a measure of the cumulative influence of identified and unidentified cardiovascular risk factors on target organ damage, changes of large artery phenotype may be causative in the pathogenesis of cardiovascular events. ${ }^{1}$ An expert consensus document on arterial stiffness has been previously published. ${ }^{3}$ In this document, more than

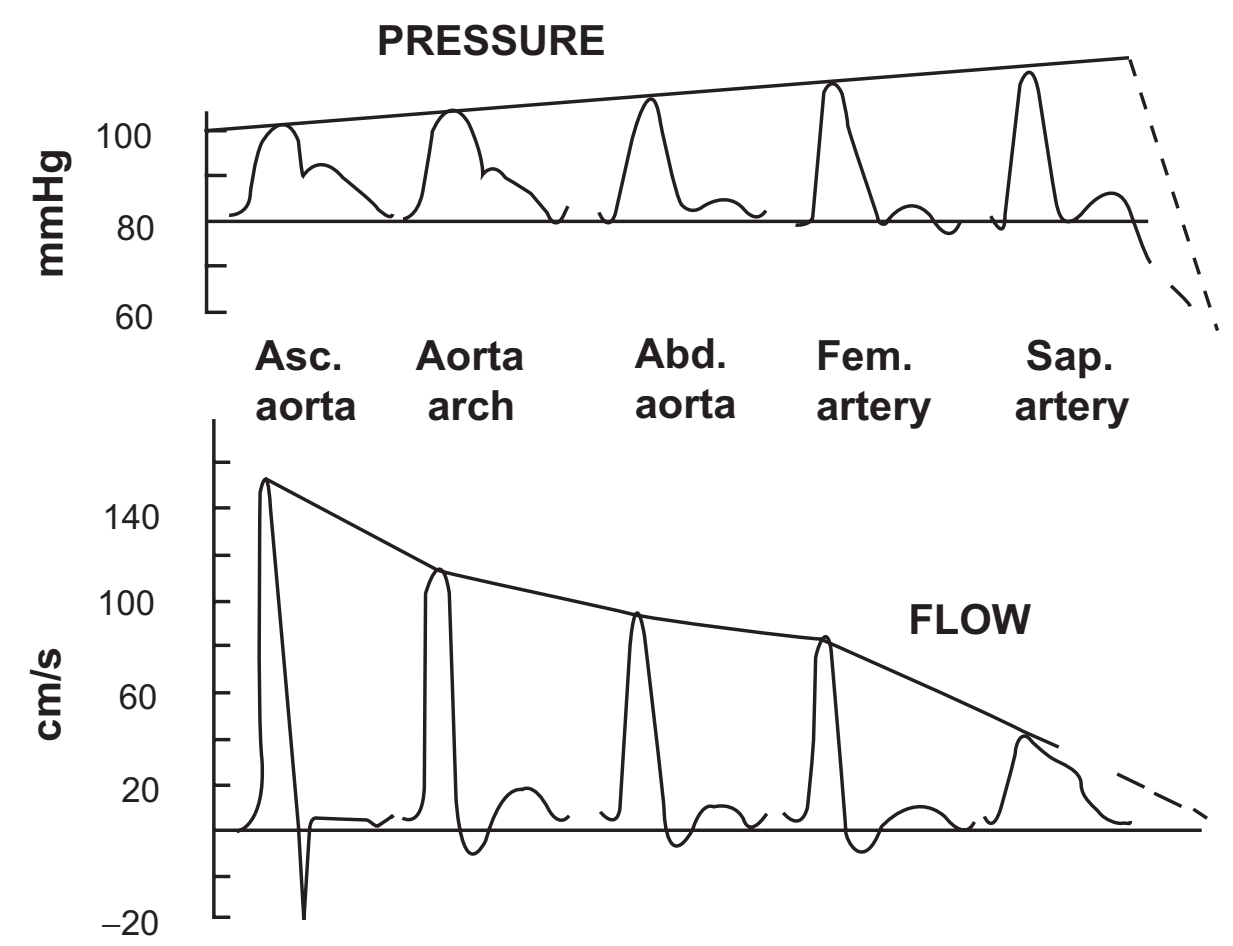

Figure I Change in contours in pressure wave (top) and flow wave (bottom) between the ascending aorta and the saphenous artery. Reproduced with permission from Agabiti-Rosei E, Mancia G, O'Rourke MF, et al Central blood pressure measurements and antihypertensive therapy: a consensus document. Hypertension. 2007;50:I54-160. ${ }^{4}$ Copyright (C) 2007 Lippincott Williams \& Wilkins. 


\section{Systolic pressure}

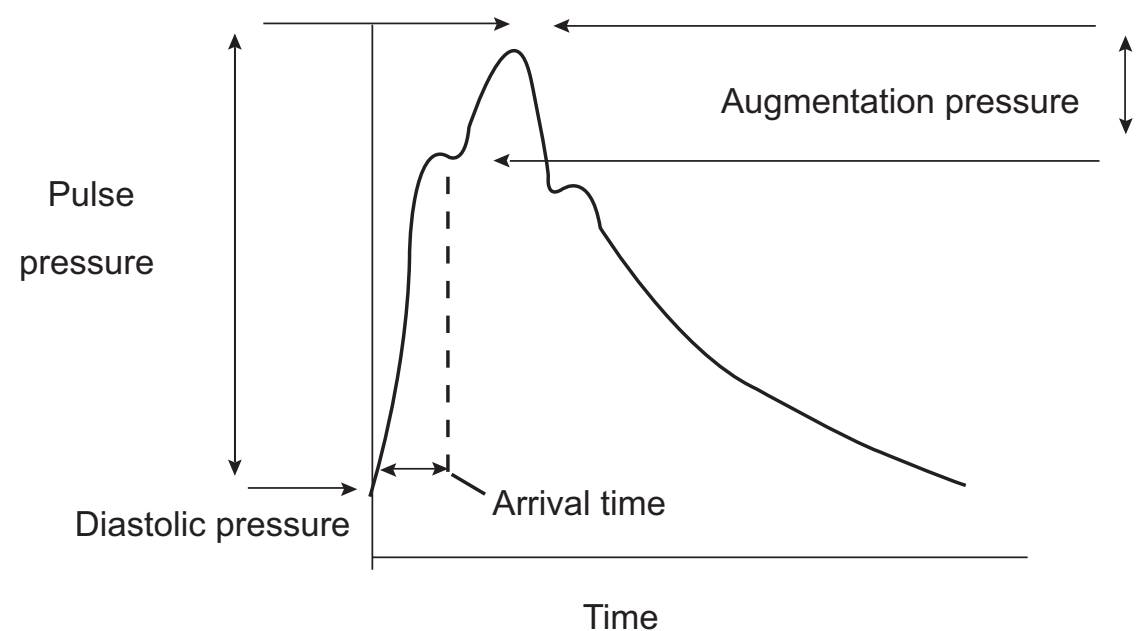

Figure 2 Central pressure waveform. The height of the late systolic peak above the inflection defines the augmented pressure, and the ratio of augmented pressure to pulse pressure identifies the augmentation index (in percent). Reproduced with permission from Agabiti-Rosei E, Mancia G, O'Rourke MF, et al. Central blood pressure measurements and antihypertensive therapy: a consensus document. Hypertension. 2007;50:154-160. ${ }^{4}$ Copyright (c) 2007 Lippincott Williams \&Wilkins.

11 longitudinal studies have been listed demonstrating that a simple measure of aortic stiffness through carotid-femoral PWV yielded prognostic values beyond and above traditional risk factors. ${ }^{3}$

In addition, increased aortic augmentation index is associated with coronary artery disease. ${ }^{4}$ Central pressures also correlate with cardiovascular risk not only in patients with atherosclerotic disease but also in apparently healthy subjects. The late systolic augmentation of the central pressure waveform is associated with an increase in left ventricular mass index independent of age and mean blood pressure ${ }^{4}$ and carotid systolic blood pressure is an independent determinant of left ventricular wall thickness. Moreover, central pressure is also more closely related than brachial pressure to other important cardiovascular intermediate end points, such as vascular hypertrophy, extent of carotid atherosclerosis, and ascending aorta diameter. ${ }^{4}$

\section{Arterial stiffness and antihypertensive treatment}

The effects of antihypertensive treatment with angiotensin converting enzyme (ACE) inhibitors on arterial stiffness and wave reflections were investigated by evaluation of brachial and carotid systolic blood pressure and pulse pressure (indirect indices of arterial stiffness) in the REASON Study (preterax in REgression of Arterial Stiffness in a contrOlled double-bliNd study) ${ }^{8}$ and further firmly confirmed. ${ }^{9,10}$ The REASON Study was a controlled trial that compared the $\beta$-blocking agent atenolol to a low dose combination of the diuretic indapamide with the ACE inhibitor perindopril. After 1 year, for the same diastolic blood pressure reduction, the combination of perindopril and indapamide induced a more pronounced reduction of brachial (peripheral artery) and carotid (central artery) systolic blood pressure or pulse pressure than atenolol. ${ }^{8}$ The more evident reduction of central pulse pressure induced by the combination perindoprilindapamide was associated to a more pronounced reduction of cardiac mass. ${ }^{11}$ The two drug regimens induced the same aortic PWV reduction as a result of the comparable decreases of mean or diastolic arterial pressures. ${ }^{12}$ The major difference between the two therapeutic approaches was that perindopril/indapamide but not atenolol reduced carotid augmentation index, a reliable marker of carotid wave reflections. ${ }^{12}$ Several mechanisms may be involved in the observed differences between the two therapeutic approaches. The atenolol-induced heart rate decrease may have caused the maintenance of disturbed wave reflections, ${ }^{12}$ since it has been previously demonstrated that a slow heart rate can also affect pulse wave velocity and augmentation of central aortic systolic pressure. ${ }^{13}$ However, a bradycardiac response was observed only within the first 6 months of treatment. ${ }^{8}$ It is possible that perindopril, but not atenolol, may have improved micro and macrovascular structure, by preventing structural alterations at different levels, and this aspect was previously addressed in details. ${ }^{12}$ In addition, ACE inhibitors, but not atenolol, are known to reduce reflection coefficients, ${ }^{14,16}$ thus reducing the reflection of waves from the microcirculation toward large arteries. ${ }^{12}$ In the CAFE 
study (Conduit Artery Function Evaluation), ${ }^{10}$ the different effects of atenolol/hydrochlorothiazide and amlodipine/ perindopril on central blood pressure accounted probably for a significant part of the different effect on cardiovascular outcome observed in the ASCOT trial (Anglo-Scandinavian Cardiac Outcomes Trial), in which an advantage of the combination ACE inhibitor-calcium channel blocker was clearly observed. A more pronounced and favorable effect of calcium channel blockers, diuretics and ACE inhibitors compared with $\beta$-blockers on central aortic systolic blood pressure or central augmentation pressure was also observed by Morgan et al. ${ }^{17}$

However, it should be noted that, in the previously mentioned studies, the $\beta$-blocker investigated as the comparator drug was almost always atenolol. It is conceivable that newer $\beta$-blockers with additional vasodilating properties, such as nebivolol or carvedilol, which may possess favorable effects on carbohydrate and lipid metabolism, as well as on endothelial function and on oxidative stress, may have different and more favorable effects on arterial stiffness, as compared with atenolol.

\section{Nebivolol, endothelial function and oxidative stress}

Nebivolol is a third generation $\beta$-adrenergic receptor-blocking drug. ${ }^{18,19}$ It is a racemic mixture of D- and L-enantiomers, of which D-nebivolol is considered to be a highly selective $\beta$-adrenergic receptor antagonist. In addition, nebivolol has been demonstrated to possess vasodilator properties both in experimental animals and in humans. This effect may be attributable to the ability of nebivolol to increase nitric oxide (NO) bioavailability, as demonstrated in animals, human volunteers and hypertensive patients. ${ }^{18,20-22}$ Nebivolol may also possess antiproliferative properties that are potentially useful in terms of regression of vascular structural changes, as frequently observed in hypertensive patients. ${ }^{23} \mathrm{New}$ important findings on the metabolic profile of nebivolol and on its protective effects on oxidative stress were recently made available. Fratta Pasini et $\mathrm{al}^{24}$ have demonstrated that nebivolol decreases oxidative stress in essential hypertension and increases NO by reducing its oxidative inactivation. In fact, in 20 hypertensive patients, both nebivolol and atenolol significantly reduced blood pressure values after 4 weeks of treatment. ${ }^{24}$ Plasma and low density lipoproteins (LDL) hydroperoxides, plasma 8-isoprostanes, plasma oxidized LDL and LDL lag phase (and index of susceptibility of LDL to oxidation) were significantly improved only in patients receiving nebivolol. Similarly, there was a reduction of reactive oxygen species (ROS) and of superoxide anion concentration in cultured endothelial cells exposed to oxidative stress after incubation with plasma of patients treated with nebivolol, while no effect was seen with plasma obtained from patients treated with atenolol. Furthermore, the reduction of $\mathrm{NO}$ production by endothelial cells induced by oxidative stress was significantly lower in patients receiving nebivolol compared with those given atenolol. These findings strongly support the hypothesis that nebivolol may increase NO by reducing its oxidative inactivation. In this regard, a relevant role might be played by an inhibition of superoxide formation by NADPH oxidase through a prevention of NADPH subunit assembly. ${ }^{25}$

Nebivolol might also improve endothelial function by increasing NO production through a stimulation of constitutive NO-synthase (eNOS), or by reducing oxidative inactivation of NO. Dessy et $\mathrm{al}^{26}$ suggested as a possible explanation for the stimulation of eNOS by nebivolol also the involvement of $\beta-3$ adrenoceptors. Alternatively, nebivolol might reduce asymmetric dimethylarginine (ADMA) circulating levels, being ADMA a potent inhibitor of eNOS. ${ }^{27}$

These properties of nebivolol seem to be linked to the chemical structure of the drug since they are present also in its 4-keto derivative, ${ }^{28}$ as demonstrated in a study performed in bovine aortic endothelial cells and in human umbilical vein endothelial cell culture. The observed antioxidant properties of nebivolol seem to be highly specific, since, in a clinical study, Taddei et $\mathrm{al}^{29}$ could not observe any effect on endothelial function (acetylcholine-induced vasodilatation in the forearm) and on oxidative stress using a different $\beta$-blocker, atenolol, given to 10 hypertensive patients. Therefore, available data suggest that nebivolol may exert relevant protective actions on endothelium, by increasing $\mathrm{NO}$ bioavailability. Antioxidant properties of nebivolol, and its neutral or even favorable effects on both carbohydrate and lipid metabolism, ${ }^{20,31}$ seem to be well documented. ${ }^{18}$

\section{Nebivolol and large artery stiffness}

An increased oxidative stress or a decreased NO production may be involved in the development of structural alterations in large arteries, including changes in the mechanical properties. ${ }^{1,32}$ Also in a recent evaluation of markers of vascular stiffness, performed in the Framingham population, a marker of endothelial function, namely PAI-1 production, was found to be related to central pulse pressure and to and forward pressure wave. ${ }^{33}$ Therefore, the NO-mediated effects of nebivolol might theoretically lead to a reversal 
of endothelial dysfunction and to a decrease of large artery stiffness and of systemic vascular resistance. ${ }^{34}$

Mahmud and Feely ${ }^{35}$ compared the effects of the $\beta$-blockers atenolol and nebivolol on indices of arterial stiffness in 40 subjects with untreated hypertension. Arterial stiffness was assessed in terms of carotid-femoral PWV (Complior ${ }^{\circledR}$ ) and arterial wave reflection (augmentation index by applanation tonometry, Sphygmocor $\left.{ }^{\circledR}\right)$. Both $\beta$-blockers produced an equal reduction in brachial blood pressure, but aortic pulse pressure was reduced to a greater extent by nebivolol (from $51 \pm 2$ to $35 \pm 2 \mathrm{mmHg}, \mathrm{p}<0.01)$ compared with atenolol (from $54 \pm 3$ to $43 \pm 3 \mathrm{mmHg}, \mathrm{p}<0.05$ ). PWV was decreased significantly by both therapies but only nebivolol significantly reduced augmentation index (Figure 3). In addition, whereas pulse pressure amplification decreased during treatment with atenolol, it increased during treatment with nebivolol (Figure 3). Atenolol reduced heart rate to a greater extent than nebivolol (14 \pm 3 beats per minute reduction by atenolol vs

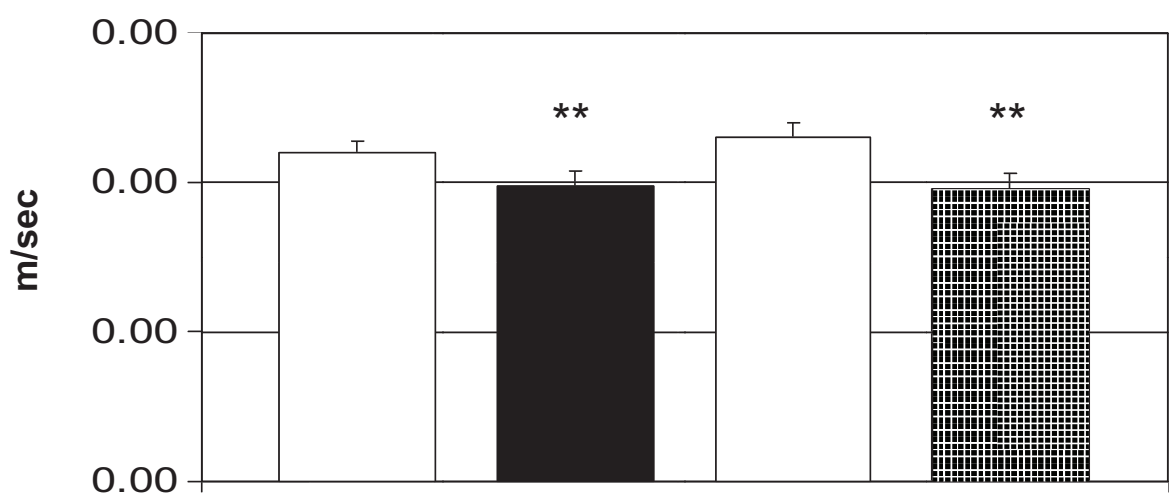

Pulse wave velocity

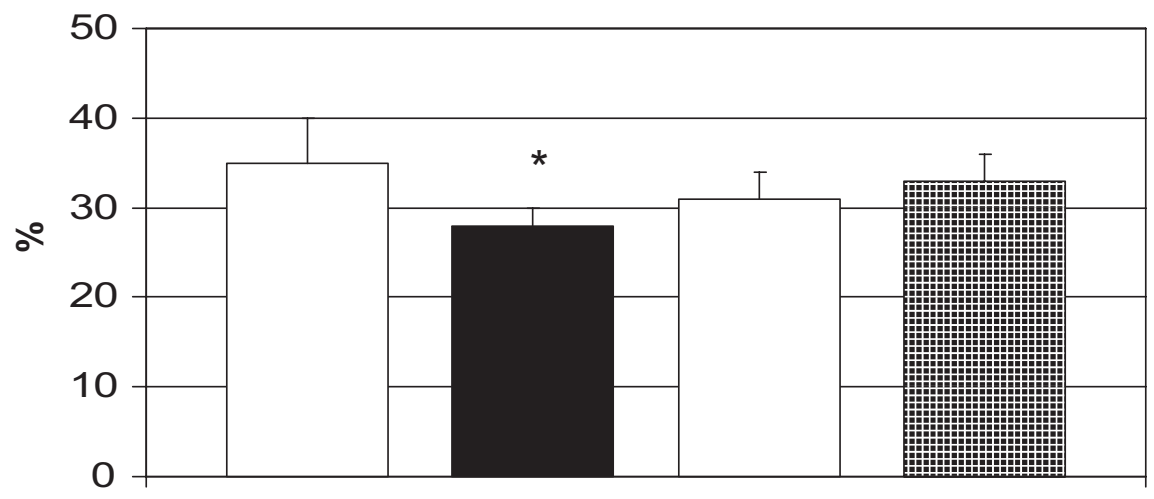

\section{Augmentation index}

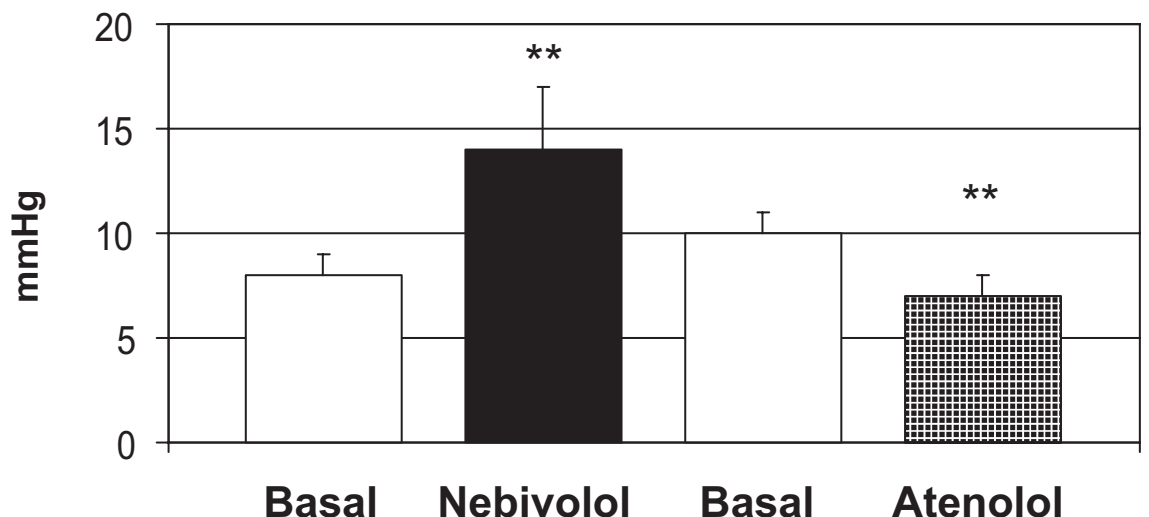

Pulse pressure amplification

Figure 3 Changes in pulse wave velocity, augmentation index and pulse pressure amplification in 40 hypertensive patients treated with nebivolol or atenolol for 4 weeks. $*=\mathrm{p}<0.05 ;{ }^{* *}=\mathrm{p}<0.01$ vs Basal. Reproduced by permission from Macmillan Publishers Ltd: Mahmud A, Feely J. Beta-blockers reduce aortic stiffness in hypertension but nebivolol, not atenolol, reduces wave reflection. Am J Hypertens. 2008;21:663-667. ${ }^{34}$ Copyright @ 2008. 
$8 \pm 2$ beats per minute reduction by nebivolol, $\mathrm{p}<0.05)$. It is possible, therefore, that nebivolol, in contrast to atenolol, may have an effect on small resistance arteries, increasing pulse pressure amplification and reducing wave reflection, possibly because of increased local levels of NO. The authors concluded that such ancillary properties may be relevant in terms of impact on hemodynamics, suggesting that $\beta$-blockers cannot be regarded as a homogeneous group in this regard. ${ }^{35}$

In a study by Dikram et $\mathrm{al}^{36}$ nebivolol and atenolol had similar effects on brachial blood pressure and aortic stiffness (Table 1). However, nebivolol reduced aortic pulse pressure more than atenolol (Table 1), and this effect may have been related to a less pronounced rise in augmentation index and to less bradycardia. When nebivolol was compared with the ACE inhibitor enalapril, in terms of effects on insulin sensitivity, hemodynamics and arterial stiffness, no difference between the two drugs was observed, thus suggesting that nebivolol shared with enalapril beneficial effects on arterial compliance and on glucose metabolism in hypertensive diabetic patients. ${ }^{37}$ The direct effects of $\beta$-blockade on PWV, which, as previously mentioned, is a robust measure of arterial distensibility, were investigated in an ovine, hind-limb animal model. ${ }^{38}$ The results demonstrated that nebivolol, but not atenolol, increases arterial distensibility, independently of any effect on blood pressure. This effect of nebivolol seemed to be mediated through the release of NO via a $\beta$-2 adrenoceptor-dependent mechanism. ${ }^{38}$
Finally, Arosio et $\mathrm{al}^{39}$ demonstrated that nebivolol and atenolol significantly reduced diastolic blood pressure and heart rate, favorably modulating response to handgrip. Nebivolol, but not atenolol, improved small artery distensibility index and endothelial function, as evaluated by endothelium-dependent cutaneous vasodilation after acetylcholine, although the distensibility index of small arteries evaluated by the authors (time to peak divided by total time of the pressure curve obtained from a digital artery) seems to have some limitations. ${ }^{40}$

In general, it is possible to conclude that the beneficial effects of nebivolol on arterial stiffness ${ }^{41-43}$ and endothelial dysfunction ${ }^{44}$ are consistently demonstrated, and differ from those observed with atenolol.

\section{Conclusions}

Several findings confirm that nebivolol, a highly selective $\beta$-1-blocker, endowed with additional vasodilating activity mediated by $\mathrm{NO}$ endothelial release, differs from other $\beta$-blocking agents, and that the combination of $\beta$ - 1 blockade and NO-mediated vasodilation leads to a broader favorable metabolic profile, and to beneficial effects on arterial stiffness, ${ }^{41,43}$ these properties may be clinically relevant in the treatment of hypertensive patients. ${ }^{45}$ In particular, antioxidant and endothelial-protective properties and neutral or favorable effects on both carbohydrate and lipid metabolisms seem to be well documented. ${ }^{18}$ These properties consistently differentiate nebivolol from non-vasodilating $\beta$-blockers, and

Table I Hemodynamic and biochemical parameters following therapy with nebivolol or atenolol

\begin{tabular}{|c|c|c|c|c|c|}
\hline Parameter & Atenolol (A) & Nebivolol (N) & Placebo & Overall significance & Significance $A$ versus $N$ \\
\hline Brachial SBP (mm Hg) & $137 \pm 3^{*}$ & $136 \pm 3^{*}$ & $149 \pm 3$ & 0.003 & 0.4 \\
\hline Brachial DBP (mm Hg) & $73 \pm 2$ & $75 \pm 2$ & $82 \pm 2$ & $<0.001$ & 0.5 \\
\hline Brachial PP (mm Hg) & $64 \pm 2^{*}$ & $61 \pm 3^{*}$ & $67 \pm 3$ & -0.2 & - \\
\hline $\operatorname{MAP}(\mathrm{mm} \mathrm{Hg})$ & $94 \pm 3^{*}$ & $95 \pm 2 *$ & $104 \pm 2$ & $<0.001$ & 0.8 \\
\hline Aortic SBP $(\mathrm{mm} \mathrm{Hg})$ & $127 \pm 3^{*}$ & $125 \pm 3^{*}$ & $|3| \pm 2$ & 0.03 & 0.4 \\
\hline Aortic DBP $(\mathrm{mm} \mathrm{Hg})$ & $73 \pm 2$ & $75 \pm 2$ & $82 \pm 2$ & $<0.001$ & 0.3 \\
\hline Aortic PP (mm Hg) & $54 \pm 2 *$ & $50 \pm 2$ & $49 \pm 2$ & $<0.001$ & 0.02 \\
\hline PP amplification & $1.20 \pm 0.02$ & $1.22 \pm 0.02$ & $1.39 \pm 0.03$ & $<0.001$ & 0.7 \\
\hline Heart rate (beats/min) & $57 \pm 1$ & $61 \pm 2$ & $80 \pm 3$ & $<0.001$ & 0.009 \\
\hline Aix (\%) & $32 \pm 2 *$ & $28 \pm 2^{*}$ & $22 \pm 2$ & $<0.001$ & 0.04 \\
\hline Aortic PWV (m/s) & $8.9 \pm 0.3^{*}$ & $9.1 \pm 0.3^{*}$ & $10.0 \pm 0.04$ & $<0.001$ & 0.2 \\
\hline
\end{tabular}

Adapted with permission from Dhakam Z, Yasmin, McEniery CM, Burton T, Brown MJ,Wilkinson IB. A comparison of atenolol and nebivolol in isolated systolic hypertension. J Hypertens. 2008; 26:35I-236. ${ }^{36}$ Copyright (C) 2008 Lippincott Williams \& Wilkins.

Notes: *indicates a significant change compared with the placebo phase for individual treatments based on custom hypothesis testing. Significance was determined using repeated-measures ANOVA for the two active drugs compared with the placebo phase. Data represent means \pm SEM, or medians (interquartile range).

Abbreviations: Aix, augmentation index; DBP, diastolic blood pressure; MAP, mean arterial pressure; PP, pulse pressure; PWV, pulse wave velocity; SBP, systolic blood pressure. 
may account for the favorable effects on arterial distensibility. Because endothelial dysfunction and arterial stiffness play an important role in the early atherosclerotic process and are associated with poor outcomes and increased mortality, independent of blood pressure, the ability of nebivolol to enhance release of endothelium-derived NO may have significant clinical implications for the use of this agent in the treatment of hypertension and cardiovascular diseases.

\section{Disclosures}

The authors have no conflicts of interest to disclose.

\section{References}

1. Boutouyrie P, Laurent S, Briet M. Importance of arterial stiffness as cardiovascular risk factor for future development of new type of drugs. Fundam Clin Pharmacol. 2008;22:241-246.

2. Mahmud A, Feely J. Spurious systolic hypertension of youth: fit young men with elastic arteries. Am J Hypertens. 2003;16(3):229-232.

3. Laurent S, Cockcroft J, Van Bortel L, et al; the European Network for Non-invasive Investigation of Large Arteries. Expert consensus document on arterial stiffness: methodological issues and clinical applications. Eur Heart J. 2006;27:2588-2605.

4. Agabiti-Rosei E, Mancia G, O’Rourke MF, et al. Central blood pressure measurements and antihypertensive therapy: a consensus document. Hypertension. 2007;50:154-160.

5. McEniery CM, Yasmin, Hall IR, Qasem A, Wilkinson IB, Cockcroft JR; ACCT Investigators. Normal vascular aging: differential effects on wave reflection and aortic pulse wave velocity: the Anglo-Cardiff Collaborative Trial (ACCT). Am Coll Cardiol. 2005;46(9):1753-1760.

6. Mahmud A, Feely J. Arterial stiffness is related to systemic inflammation in essential hypertension. Hypertension. 2005;46:1118-1122.

7. Amar J, Ruidavets JB, Peyrieux JC, et al. C-reactive protein elevation predicts pulse pressure reduction in hypertensive subjects. Hypertension. 2005;46:151-155.

8. London GM, Asmar RG, O’Rourke MF, Safar ME; Reason Project Investigators, Mechanism(s) of selective systolic blood pressure reduction after a low-dose combination of perindopril/indapamide in hypertensive subjects: comparison with atenolol. J Am Coll Cardiol. 2004;43:92-99.

9. Hirata K, Vlachopoulos C, Adji A, O’Rourke MF. Benefits from angiotensin-converting enzyme inhibitor 'beyond blood pressure lowering': beyond blood pressure or beyond the brachial artery? J Hypertens. 2005;23:551-556.

10. Williams B, Lacy PS, Thom SM, et al; CAFE Investigators; AngloScandinavian Cardiac Outcomes Trial Investigators; CAFE Steering Committee and Writing Committee, et al. Differential impact of blood pressure-lowering drugs on central aortic pressure and clinical outcomes: principal results of the Conduit Artery Function Evaluation (CAFÉ) study. Circulation. 2006;113:1213-1225.

11. De Luca N, Asmar R, London GM, O’Rourke MF, Safar ME; REASON Project Investigators. Selective reduction of cardiac mass and central blood pressure on low-dose combination perindopril/indapamide in hypertensive subjects. J Hypertens. 2004;22:1623-1630.

12. Safar ME, Rizzoni D, Blacher J, Muiesan ML, Agabiti-Rosei E. Macro and microvasculature in hypertension: therapeutic aspects. J Hum Hypertens. 2008;22(9):590-595.

13. Wilkinson IB, MacCallum H, Flint L, Cockcroft JR, Newby DE, Webb DJ: The influence of heart rate on augmentation index and central arterial pressure in humans. J Physiol (Lond). 2000;525:263-270.

14. Ting CT, Yang TM, Chen JW, Chang MS, Yin FC. Arterial hemodynamics in human hypertension. Effects of angiotensin converting enzyme inhibition. Hypertension. 1993;22:839-846.
15. Chen CH, Ting CT, Lin SJ, Hsu FCP, Siu CO, Chou P, et al. Different effects of fosinopril and atenolol on wave reflections in hypertension. Hypertension. 1995;25:1034-1041.

16. Ting CT, Chen C-H, Chang M-S, Yin FCP. Short- and long-term effects of antihypertensive drugs on arterial reflections compliance and impedance. Hypertension. 1995;26:524-530.

17. Morgan T, Lauri J, Bertram D, Anderson A. Effect of different antihypertensive drug classes on central aortic pressure. Am J Hypertens. 2004;7(2):118-123.

18. Agabiti Rosei E, Rizzoni D. Metabolic profile of nebivolol, a beta-adrenoceptor antagonist with unique characteristics. Drugs. 2007;67:1097-1107.

19. Broeders MAW, Doevendans PA, Bekkers BCAM, et al. Nebivolol: a third-generation $\beta$-blocker that augments vascular nitric oxide release. Endothelial $\beta_{2}$-adrenergic receptor-mediated nitric oxide production. Circulation. 2000;102:677-682.

20. Cockcroft JR, Chowienczyk PJ, Brett SE, et al. Nebivolol vasodilates human forearm vasculature: evidence for an L-arginine/NO-dependent mechanism. J Pharmacol Exp Ther. 1995;274:1067-1071.

21. Tzemos N, Lim PO, MacDonald TM. Nebivolol reverses endothelial dysfunction in essential hypertension. A randomised, double blind crossover study. Circulation. 2001;104:511-514.

22. Gupta S, Wright HM. Nebivolol: a highly selective beta1-adrenergic receptor blocker that causes vasodilation by increasing nitric oxide. Cardiovasc Ther. 2008;26(3):189-202.

23. Andre DE, Arnet U, Yang Z, Luscher TF. Nebivolol inhibits human aortic smooth muscle cell growth: effects on cell cycle regulatory proteins. J Cardiovasc Pharmacol. 2000;35:845-848.

24. Fratta Pasini A, Garbin U, Nava MC, et al. Nebivolol decreases oxidative stress in essential hypertensive patients and increases nitric oxide by reducing its oxidative inactivation. J Hypertens. 2005;23:589-596.

25. Oelze M, Daiber A, Brandes RP, et al. Nebivolol inhibits superoxide formation by NADPH oxidase and endothelial dysfunction in angiotensin II-treated rats. Hypertension. 2006;48(4):677-684.

26. Dessy C, Saliez J, Ghisdal P, et al. Endothelial beta3-adrenoreceptors mediate nitric oxide-dependent vasorelaxation of coronary microvessels in response to the third-generation beta-blocker nebivolol. Circulation. 2005;112(8):1198-1205.

27. Pasini AF, Garbin U, Stranieri C, et al. Nebivolol treatment reduces serum levels of asymmetric dimethylarginine and improves endothelial dysfunction in essential hypertensive patients. Am J Hypertens. 2008;21(11):1251-1257.

28. Cominacini L, Fratta Pasini A, Garbin U, et al. Nebivolol and its 4-keto derivative increase nitric oxide in endothelial cells by reducing its oxidative inactivation. J Am Coll Cardiol. 2003;42:1838-1844.

29. Taddei S, Virdis A, Ghiadoni L, et al. Effect of calcium antagonist or beta blockade treatment on nitric oxide-dependent vasodilation and oxidative stress in essential hypertensive patients. J Hypertens. 2001;19:1379-1386.

30. Poirier L, Cleroux J, Nadeau A, Lacourciere Y. Effects of nebivolol and atenolol on insulin sensitivity and haemodynamics in hypertensive patients. J Hypertens. 2001;19:1429-1435.

31. Fogari R, Zoppi A, Lazzari P, et al. Comparative effects of nebivolol and atenolol on blood pressure and insulin sensitivity in hypertensive subjects with type II diabetes. J Hum Hypertens. 1997;11:753-757.

32. Cockcroft J. A review of the safety and efficacy of nebivolol in the mildly hypertensive patient. Vasc Health Risk Manag. 2007;3:909-917.

33. Lieb W, Larson MG, Benjamin EJ, et al. Multimarker approach to evaluate correlates of vascular stiffness: the Framingham Heart Study. Circulation. 2009;119(1):37-43.

34. Gray CL, Ndefo UA. Nebivolol: a new antihypertensive agent. Am J Health Syst Pharm. 2008;65:1125-1233.

35. Mahmud A, Feely J. Beta-blockers reduce aortic stiffness in hypertension but nebivolol, not atenolol, reduces wave reflection. Am J Hypertens. 2008;21:663-667.

36. Dhakam Z, Yasmin, McEniery CM, Burton T, Brown MJ, Wilkinson IB. A comparison of atenolol and nebivolol in isolated systolic hypertension. J Hypertens. 2008;26:351-236. 
37. Kaiser T, Heise T, Nosek L, Eckers U, Sawicki PT. Influence of nebivolol and enalapril on metabolic parameters and arterial stiffness in hypertensive type 2 diabetic patients. $J$ Hypertens. 2006;24: 1397-1403.

38. McEniery CM, Schmitt M, Qasem A, et al. Nebivolol increases arterial distensibility in vivo. Hypertension. 2004;44:305-310.

39. Arosio E, De Marchi S, Prior M, Zannoni M, Lechi A. Effects of nebivolol and atenolol on small arteries and microcirculatory endothelium-dependent dilation in hypertensive patients undergoing isometric stress. J Hypertens. 2002;20(9):1793-1797.

40. Van Bortel L. Focus on small artery stiffness. J Hypertens. 2002;20: 1707-1709.
41. Pedersen ME, Cockcroft JR. The latest generation of beta-blockers: new pharmacologic properties. Curr Hypertens Rep. 2006;8:279-286.

42. Cockcroft JR. Exploring vascular benefits of endothelium-derived nitric oxide. Am J Hypertens. 2005;18(12 Pt 2):177S-183S.

43. Cockcroft J. Nebivolol: a review. Expert Opin Pharmacother. 2004:5:893-899.

44. Thuillez C, Richard V. Targeting endothelial dysfunction in hypertensive subjects. J Hum Hypertens. 2005;19 Suppl 1:S21-S25.

45. Zanchetti A. Clinical pharmacodynamics of nebivolol: new evidence of nitric oxide-mediated vasodilating activity and peculiar haemodynamic properties in hypertensive patients. Blood Press. 2004;1 Suppl: $17-32$.

\section{Publish your work in this journal}

Vascular Health and Risk Management is an international, peerreviewed journal of therapeutics and risk management, focusing on concise rapid reporting of clinical studies on the processes involved in the maintenance of vascular health; the monitoring, prevention and treatment of vascular disease and its sequelae; and the involvement of metabolic disorders, particularly diabetes. This journal is indexed on PubMed Central and MedLine. The manuscript management system is completely online and includes a very quick and fair peer-review system, which is all easy to use. Visit http://www.dovepress.com/ testimonials.php to read real quotes from published authors. 